\title{
A Local Type-2 Fuzzy Set Based Technique For He Stain Image Enhancement
}

Técnica local basada en conjuntos difusos de tipo 2 para mejorar la imagen de manchas

Uma técnica baseada em conjunto difuso de tipo 2 local
para melhoramento de imagem com coloração HE

\author{
Dibya Jyoti Bora ${ }^{1}$ \\ Rubul Kumar Bania² \\ Che-Ngoc ${ }^{3}$
}

Received: May $17^{\text {th }}, 2019$

Accepted: July $22^{\text {th }}, 2019$

Available: September 16 ${ }^{\text {th }}, 2019$

How to cite this article:

D. Jyoti Bora, R. Kumar Bania, and Che-Ngoc, "A Local Type-2 Fuzzy Set Based Technique

For He Stain Image Enhancement," Revista Ingeniería Solidaria, vol. 15, no. 3, 2019.

doi: https://doi.org/10.16925/2357-6014.2019.03.02

Artículo de investigación. https://doi.org/10.16925/2357-6014.2019.03.02

1 School of Computing Sciences, the Assam Kaziranga University, Jorhat, Assam,India.

ORCID: https://orcid.org/0000-0001-7809-5220

E-mail: dibyajyotibora@kazirangauniversity.in

2 Assistant Professor, NEHU, Meghalaya, India.

ORCID: https://orcid.org/0000-0001-6294-0231

3 Ton Duc Thang University, Ho Chi Minh City, Vietnam.

E-mail: chengocha@tdtu.edu.vn 


\section{Abstract}

The proposed approach in the paper comes under "Advanced Soft Computing Based Medical Image Processing Research" and the work has been conducted by Dr. Dibya Jyoti Bora (Assistant Professor), School of Computing Sciences, The Assam Kaziranga University, Jorhat, Assam in the year 2018-2019.

Introduction: HE stain images, although considered as the golden standard for medical image diagnosis, are still found to suffer from poor contrast and degradation in color quality. In this paper, a Type-2 fuzzy set-based enhancement technique is proposed for HE stain image enhancement with special care towards color-based computations and measurements.

Methods: This paper introduces a new approach based on Type-2 fuzzy set for HE stain image enhancement where Bicubic Interpolation plays an important part. Unsharp Masking is also employed as a post enhancement factor.

Results: From the results, it is clearly visible that cell nuclei and other cell bodies are easily distinguishable from each other in the enhanced result produced by our proposed approach. It implies that vagueness in the edges surrounding the objects in the original image is removed to an acceptable level.

Conclusions: The proposed approach is found to be, through both subjective and objective evaluations, an efficient preprocessing technique for a better HE stain image analysis.

Originality: The ideas involved in this paper are original. If work by other researchers are mentioned in any part of the paper, then they are cited properly.

Limitation: The relatively high time complexity is the only limitation associated with the proposed approach.

Keywords: Bicubic Interpolation, HE stains image, color image processing, color image enhancement, HSV color space, Type-2 fuzzy set.

\section{Resumen}

El enfoque propuesto en el artículo se encuentra en el proyecto "Investigación avanzada de procesamiento de imágenes médicas basadas en computación suave", el trabajo ha sido realizado por el doctor Dibya Jyoti Bora (profesor asistente), de la Facultad de Ciencias de la Computación, Universidad de Assam Kaziranga, Jorhat, Assam en el año 2018-2019.

Introducción: las imágenes de tinción $\mathrm{HE}$, aunque consideradas como el estándar ideal para el diagnóstico de imágenes médicas, aún sufren de poco contraste y degradación en la calidad del color. En este documento se propone una técnica de mejora basada en conjuntos difusos tipo 2 para optimizar la imagen de tinción HE con especial cuidado hacia los cálculos y mediciones basados en el color.

Métodos: este documento presenta un nuevo enfoque basado en el conjunto difuso tipo 2 para mejorar la imagen de tinción $\mathrm{HE}$, donde la interpolación bicúbica juega un papel importante. La máscara de desenfoque también se emplea como factor de mejora posterior.

Resultados: a partir de los resultados es claramente visible que los núcleos celulares y otros cuerpos celulares son fácilmente distinguibles entre sí en el resultado mejorado producido por el enfoque propuesto. Esto implica que la vaguedad en los bordes que rodean los objetos en la imagen original se elimina a un nivel aceptable.

Conclusiones: se encuentra que el enfoque es, a través de evaluaciones tanto subjetivas como objetivas, una técnica de preprocesamiento eficiente para un mejor análisis de imagen de tinción $\mathrm{HE}$.

Originalidad: las ideas involucradas en este documento son originales. Si el trabajo de otros investigadores se menciona en alguna parte del artículo se citan correctamente.

Limitación: la complejidad de tiempo relativamente alta es la única limitación asociada con el enfoque propuesto.

Palabras clave: interpolación bicúbica, imagen de tinción $\mathrm{HE}$, procesamiento de imagen en color, mejora de imagen en color, espacio de color HSV, conjunto difuso tipo 2. 


\section{Resumo}

A abordagem proposta no artigo vem do trabalho "Advanced Soft Computing Based Medical Image Processing Research" (Pesquisa de processamento de imagem médica baseada em computação suave avançada), realizado pelo Dr. Dibya Jyoti Bora (Professor Assistente), da Escola de Ciências da Computação do The Assam Kaziranga University, em Jorhat, Assam, em 2018-2019.

Introdução: embora sejam consideradas o principal padrão para o diagnóstico de imagens médicas, as imagens com coloração HE ainda sofrem com pouco contraste e degradação na qualidade da cor. Neste artigo, uma técnica de melhoramento baseada em um conjunto difuso de tipo 2 é proposta para melhorar a imagem com coloração $\mathrm{HE}$, com um cuidado especial a respeito dos cálculos e das medidas baseados em cores.

Métodos: este trabalho introduz uma nova abordagem baseada no conjunto difuso de tipo 2 para melhoramento de imagem com coloração HE no qual a interpolação bicúbica tem um papel importante. 0 filtro de desfoque unsharp masking também é empregado como um fator posterior de melhoramento.

Resultados: a partir dos resultados, é bastante visível que os núcleos e outras partes da célula são facilmente diferenciados uns dos outros no resultado melhorado que é produzido pela abordagem que propomos. Isso implica que a imprecisão nas bordas que circundam os objetos na imagem original é eliminada a um nível aceitável.

Conclusões: notou-se, por meio de avaliações subjetivas e objetivas, que a abordagem proposta é uma técnica de pré-processamento eficiente para melhorar a análise de imagem com coloração HE.

Originalidade: as ideias envolvidas neste artigo são originais. Se o trabalho de outros pesquisadores é citado em qualquer parte deste artigo, eles foram citados adequadamente.

Limitação: a complexidade de tempo relativamente alta é a única limitação associada à abordagem proposta.

Palavras-chave: interpolação bicúbica, coloração HE, processamento de imagens coloridas, melhoramento de imagens coloridas, modelo HSV, conjunto difuso de tipo 2.

\section{INTRODUCTION}

In medical diagnosis, HE stain images are frequently used for detecting cancer and other serious diseases. The accurate results of this diagnosis process are totally dependent on the quality of the input image. It is found that medical images often suffer from low contrast issues. The fuzzy behavior of the boundaries of the images makes it difficult for traditional techniques to enhance these images. So, Type-2 fuzzy set based techniques have been selected for the contrast enhancement purpose. The proposed technique is an extended version of the one that has been introduced in [1]. Here, the color computation part has been taken very seriously. RGB color space is not suitable for color image enhancement purpose as hue values are associated with each of the three layers R, G, B [2]. So, there may arise the problem of a color mismatch after the enhancement process. Hence, we go for other color spaces than RGB. LAB and HSV color spaces are two frequently adopted color spaces in color image processing but it has been found through experimentation that HSV color space is more efficient than LAB [3]. Hence, we have adopted an HSV color space for our proposed technique. One special reason for this is that HSV color space has a 
devoted V-channel especially for luminance level measurements and so it acts as an intensity channel. Our proposed technique is based on the concept that the enhancement can be achieved without altering the hue values if we perform the enhancement only on the intensity channel [2]. An unsharp masking based technique is used as a post-processing technique to remove unwanted blurriness that may be occurred after the fuzzy enhancement. The remaining portion of the paper is organized as follows: In section 2, a review of previous work done in the field with motivation for the present work is presented. The steps involved in the proposed approach are clearly illustrated with the flowchart in section 3. Section 4 and its subsections explain different techniques and areas involved in the proposed approach. Section 5 is the experiments and results discussion section. Finally, the conclusion is drawn in section 6.

\section{RELATED WORKS AND MOTIVATION FOR PROPOSED APPROACH}

In this section, we have presented some of the important contributions in this area which help us to understand problems and thereby motivate us towards the development of the proposed approach.

In [3], the authors introduced a new fuzzy Type-2 Possibilistic C-Means clustering (PCM) method for image enhancement. It is found the performance is better than Fuzzy C-Mean (FCM) and Possibilistic C-Means (PCM). The reason behind is that both FCM and PCM are based on Type-1 fuzzy logic. While Type-2 fuzzy set-based techniques have much better performance than Type-1 fuzzy set-based ones.

In [4], Chaira proposed intuitionistic fuzzy set-based theory image enhancement techniques. These techniques take into account two uncertainties and hence, there is a good possibility of better enhancement of medical images. Then in [5], Chaira introduced a new Type-2 fuzzy set-based medical image contrast enhancement technique where she used Hamacher T co-norm as an aggregation operator to form a new membership function with proper upper and lower membership function. The enhanced image is the one produced from the new membership function. The efficiency of the Type-2 based enhancement techniques is found to be better than the other traditional techniques including intuitionistic ones.

Gu et al. [6] applied the Y-H(Young-Helmholtz) transformation with an adaptive equalization of intensity numbers matrix histogram for the enhancement of color medical images. The contrast is enhanced by adaptive histogram equalization and thereby suppresses the noise present in the original image. Then they carry out the 
inverse transformation from $\mathrm{Y}-\mathrm{H}$ to RGB to show the enhanced color image without affecting hue and saturation values. The experiments proved that the proposed technique is well suitable for diagnosis of medical images as it carries low computational complexity.

Ensafi et al. [7] discussed the solutions for the image enhancement problem using Type-2 based enhancement techniques. The authors introduced a new Type-2 fuzzy membership function for this purpose. Zarinbal et al. also proposed a Type-2 based enhancement technique for image enhancement and analyzed its performance in detecting noise pixels and improving image quality [8]. The proposed method succeeds to produce the better image quality and could preserve edges and other details of images better than the other methods.

Bora [9] has introduced a new efficient technique for color image enhancement. He claimed that removal of noise first and then contrast enhancement on the noisefree version as the mandatory steps in the image enhancement process. A new noise removal technique Improved_Median() is introduced for the noise removal process and AA_CLAHE() is proposed for the contrast enhancement task. HSV color space is found to be very useful in the proposed technique for the enhancement operation.

So, by analyzing the previous work in this field, we have come to the conclusion that medical images are very difficult to be dealt with via traditional state of the art algorithms. The main reason is due to the fuzzy behavior of the boundaries of such images. HE stain images are the commonly used images for medical diagnosis of serious diseases and in this case, the quality of image matters a lot for an accurate diagnosis process. Primarily, the color images need special treatment due to the hue information involved. So, we have been motivated towards developing a new technique for HE stain image enhancement that is based on the Type-2 fuzzy set and for the color computations we have adopted HSV color space. The work presented by Ensafi and Chaira [5][7] aided us in the development and formulation of the Type-2 fuzzy set membership function presented in this paper.

\section{STEPS INVOLVED IN THE PROPOSED APPROACH}

The whole enhancement process consists of two phases: First pre-enhancement using a Type-2 fuzzy set-based technique and the second stage involves post enhancement using an unsharp masking based technique. 


\subsection{FIRST PHASE}

1. Input HE stain image.

2. Conversion of color space from RGB to HSV takes place.

3. Extract $\mathrm{V}$-channel.

4. The extracted $\vee$-channel undergoes contrast improvement with the proposed local_type2_fuzzy() method. This outputs the contrast-enhanced $\mathrm{V}^{\prime}$ - channel.

\subsection{SECOND PHASE}

1. The $V^{\prime}$ - channel is passed to the proposed Unsharp_Mask() and it outputs a V"-channel.

2. The $\mathrm{V}$-channel(obtained at step 3 of phase 1 ) is replaced with the $V^{\prime \prime}$ channel. This enhances the image in the HSV color space.

3. HSV to RGB conversion takes place to obtain the final enhanced color image.

The above steps can be clearly depicted in the following flowchart:

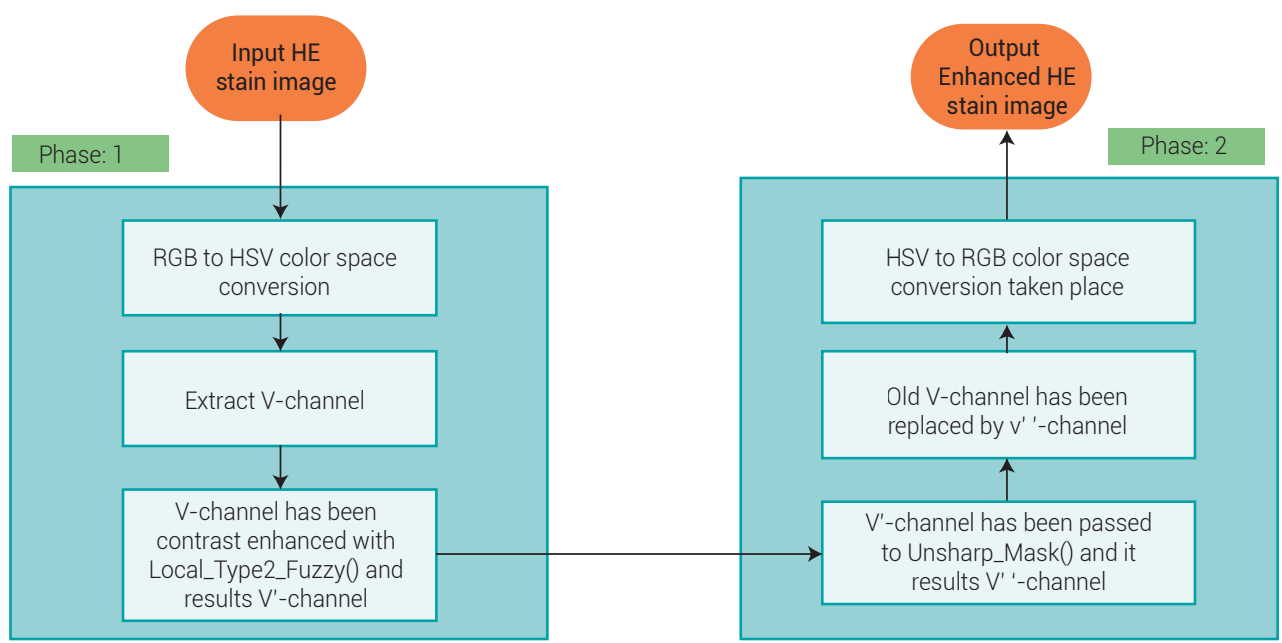

Figure 1. Flowchart of the proposed approach

Source: own work 


\section{MATERIALS AND METHODS}

In this section, we are going to discuss the different terminologies and the proposed techniques in detail:

\subsection{HE STAIN IMAGES}

HE stain image is the most widely used in medical diagnosis and often regarded as the golden standard in histology and pathology laboratories [10][11][12]. Actually, most cells are colorless and transparent and hence very difficult to analyze. The histological sections should be stained in such a way these cells should be visible [12]. HE stain is one of the popular techniques. This staining method involves the usage of hematoxylin and eosin which color nuclei and cytoplasm differently [12]. Here, hematoxylin is a dark blue or violet stain which is Basic/Positive and Eosin is a red or pink stain that is Acidic/Negative. A combination of hematoxylin and eosin generally produces blues, violets, and reds. Because of the long history of HE staining, well-established methods, and an incredible amount of data and publications, there is a strong belief among many pathologists that HE staining will continue to be the universal practice over the next 50 years [13]. However, these images suffer from poor contrast and vagueness in the boundary regions and so a proper enhancement technique is required to improve the quality of these images.

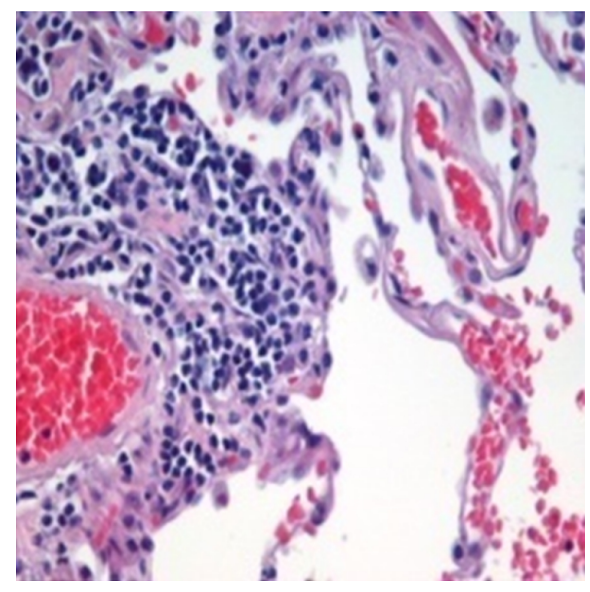

Figure 2. Histologic specimen of human lung tissue stained with hematoxylin (violets) and eosin (reds) Source: [14] 


\subsection{HSV COLOR SPACE}

To describe the organization of different colors of an image, we need a mathematical model known as color space. Color space characterizes different color attributes with respect to three or more components that facilitate the process of learning precisely what each color spectrum looks like [15][16]. RGB, LAB, HSV are some popular color spaces and RGB is the default one in most cases. In our previous work, a LAB color space was used [1]. But experiments prove that HSV color space is more efficient than LAB color space for color image pre-processing tasks [17]. Also, HSV color space has a very special characteristic of organizing any color image in the same way that our human eyes can perceive. This color space consists of three channels: Hue $(H)$, Saturation(S) and Value (V). Here, hue is an angle in the range $[0,2 \pi]$ and is directly related to color. Its different values represent different colors. The distribution of different colors with respect to hue values (ranges 0 to $2 \pi$ ) can be shown in the following color wheel diagram [15]. The color first starts with red and, as the hue value changes, it then changes in the following pattern:

$$
\text { red } \rightarrow \text { yellow } \rightarrow \text { green } \rightarrow \text { cyan } \rightarrow \text { blue } \rightarrow \text { magenta } \rightarrow \text { red }
$$

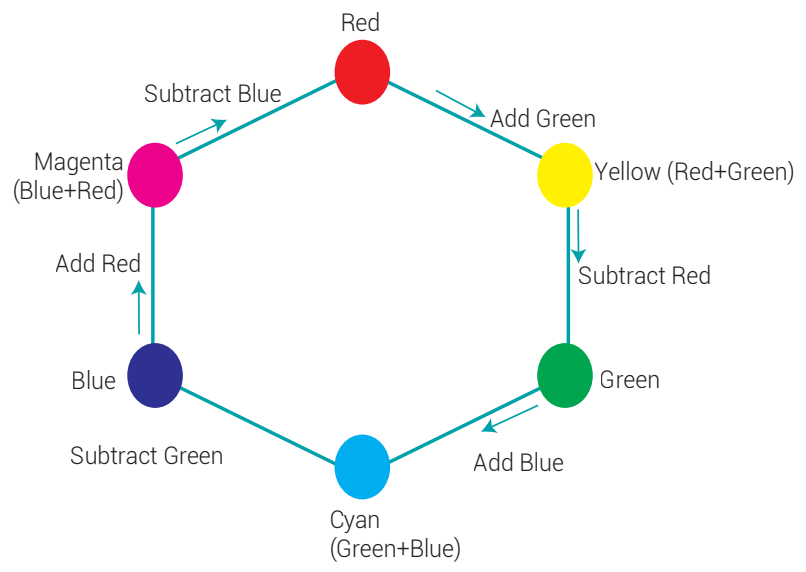

Figure 3. Color Wheel Showing Distribution of Different Colors in HSV Color Space with Respect to Different Values of $V$ Source: own work

Saturation is used to describe how pure the hue is with respect to a white reference and is measured as a radial distance from the central axis with values between 0 at the center to 1 at the outer surface. Finally, the value channel signifies a percentage value going from 0 to 100, conveying the amount of light illuminating a color. Therefore, the $\mathrm{V}$-channel is the channel for luminance level measurements and keeps the intensity values. We have employed our proposed local Type-2 fuzzy set-based 
image enhancement technique and the unsharp masking-based post enhancement technique on the $\mathrm{V}$-channel so that the hue values will not be altered.

A simple diagram for the HSV color space is [15]:

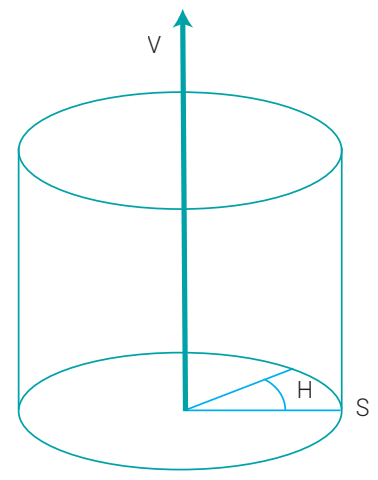

Figure 4. HSV Color Space Showing the Relation between H, S, and V Source: own work

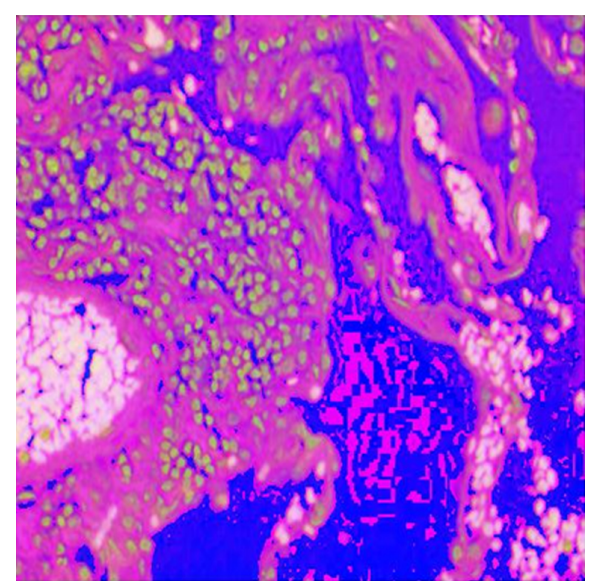

Figure 5. HSV Converted image of the HE image in figure 2

Source: own work

\subsection{Local_type2_fuzzy()}

This is a Type-2 fuzzy set-based image enhancement technique. This is the local and improved version of the one that we have introduced in [1]. Instead of applying the enhancement technique to the whole image at the same time, here, we divide the image into tiles of size $3 \times 3$ and then apply the enhancement on every tile separately. 
After that bicubic interpolation is used to merge them. Local contrast enhancement is found to be more efficient than a global one, since in the latter case, the over-enhancement may arise if a high peak occurs in the histogram [9]. In the case of medical image enhancement, over enhancement will be a serious problem as this could cause some regions to become darker or brightness factors could be increased to a level where edges surrounding different objects are hard to distinguish. In this way, the vagueness in the image will not be removed to a satisfactory level or it may be increased furthermore. So, taking this problem in hand, we introduce the local version of the Type-2 fuzzy set-based enhancement technique, local_type-2_fuzzy(). A Type2 fuzzy set can be defined as follows:

$$
A_{\text {TYPEII }}=\left\{x, \widehat{\mu}_{A}(\mathrm{x}, \mathrm{u}) \mid \forall \mathrm{x} \in \mathrm{X}, \forall u \in \mathrm{J}_{x} \subseteq[0,1]\right\}
$$

where $\widehat{\mu}_{A}(\mathrm{x}, \mu)$ is the Type-2 membership function, $\mathrm{J}_{\mathrm{x}}$ is the primary membership function of $x$.

In our case, $J_{x}$ is calculated using the following equation:

$$
J_{x}=\frac{I-I_{\min }}{I_{\max }-I_{\min }}
$$

where I is the gray level of the concerned image tile (say $A$ ) of the range 0 to $L-1$, $I_{\min }$ is the minimum and $I_{\max }$ is the maximum gray value of the image tile.

The Type-2 membership function is calculated using the following equation:

$$
\widehat{\mu}_{A}=\theta\left\{\frac{\mu_{\text {low }} \bullet \lambda+\mu_{\text {high }} \bullet(1-\lambda)}{1-(1-\lambda) \bullet \mu_{\text {low }} \bullet \mu_{\text {high }}}\right\}
$$

where, $\begin{aligned} & \mu^{\text {upper }}=\left[\mathrm{J}_{x}\right]^{\alpha} \\ & \mu^{\text {lower }}=\left[\mathrm{J}_{x}\right]^{1 / \alpha}\end{aligned}$

$$
\lambda=\frac{I_{a v g}}{L}
$$

and $\alpha(0<a \leq 1)$ is calculated on the trial and error basis. The optimum value of $\alpha$ is found through experiments and the value is 0.8. $\theta$ is termed as "degree of 
contrast enhancement" and $0<\theta<1$. We fix the value of $\theta$ as 0.5 as at this value, the result of contrast improvement is found to be optimal. Its value may be increased or decreased as per the requirement of the application.

\subsubsection{BICUBIC INTERPOLATION}

Interpolation can be defined mathematically, as a process of estimating approximate continuous values of a function. In image processing, interpolation is used to transfer an image from one resolution to another so that the quality of the image will be improved by removing artificially induced boundaries [17][18]. Interpolation methods may be adaptive or non-adaptive [19][20]. Adaptive techniques consider different features like texture, edge information, intensity transformation, etc., while non-adaptive techniques directly manipulate pixels without considering any feature like adaptive ones. DDT, ICBI, NEDI, etc. are some selective adaptive interpolation methods and nearest neighbors, bilinear and bicubic methods are a few important non-adaptive interpolation techniques. Bicubic interpolation, a non-adaptive based interpolation technique, is adopted here as the cost involved in this case is less in comparison to the adaptive ones. Bicubic interpolation is best known for its ability to produce apparent and sharper images and is also regarded the best among the non-adaptive interpolation techniques. The reason behind this is that here, the sixteen closest pixels' weighted average is used to fill the interpolated point, while in the case of nearest neighbors interpolation, only the nearest pixel is used to fill the interpolated point, and in the case of the bilinear interpolation technique, the interpolated pixel is filled with the four closest pixels' weighted average [17].

The following diagram [17] shows the use of sixteen nearest neighbor pixels in the bicubic interpolation algorithm: 


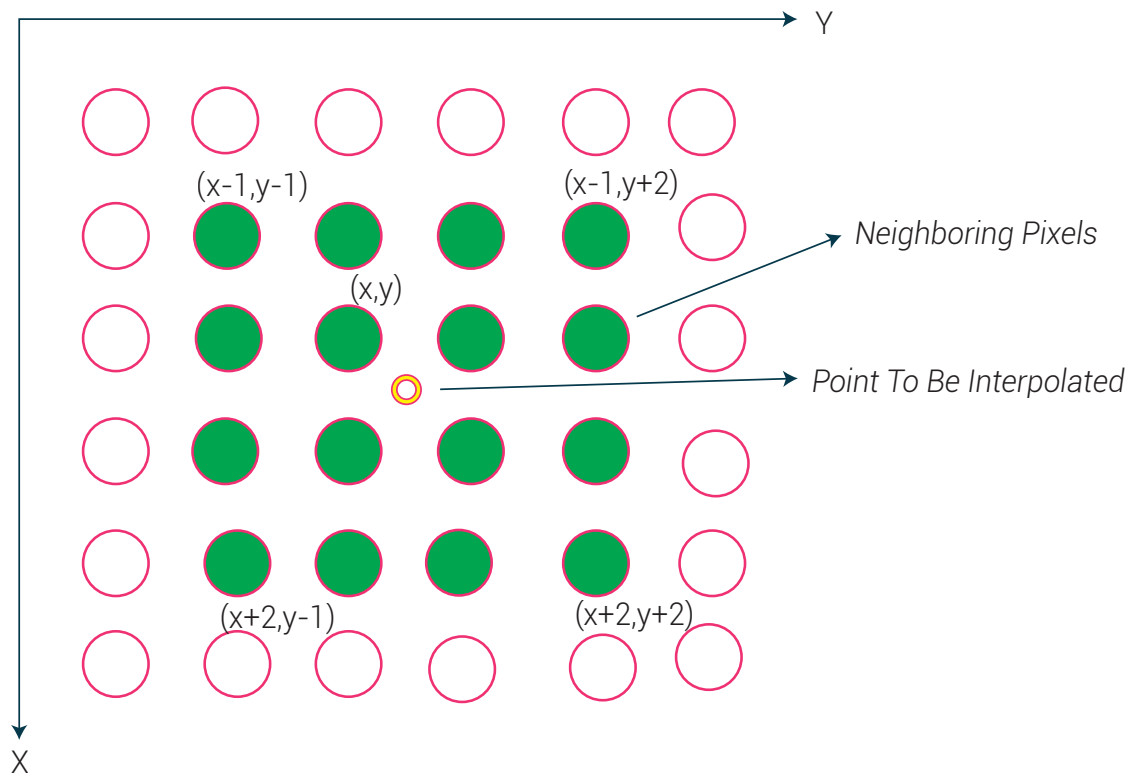

Figure 6. Bicubic Interpolation

Source: own work

The interpolation kernel, 'u' (which must be symmetric) for bicubic interpolation [18] is estimated using the following equation:

$$
u(d)=\left\{\begin{array}{cl}
\frac{3}{2}|d|^{3}-\frac{5}{2}|d|^{2}+1 & 0 \leq d<1 \\
-\frac{1}{2}|d|^{3}+\frac{5}{2}|d|^{2}-4|d|+2 & 1 \leq d<2 \\
0 & 2<d
\end{array}\right.
$$

Where ' $d$ ' is the distance between the interpolated point and the grid point to be considered.

As the bicubic interpolation algorithm succeeds in producing a clear picture quality while preserving image details in a better way than its bilinear counterpart [17] [19][20], this technique has been adopted for our local_type2_fuzzy() technique.

\subsection{UNSHARP MASKING, Unsharp_Mask()}

Unsharp masking is a very efficient image sharpening technique [21, 22]. The working methodology of unsharp masking is very simple. It first finds out the blurred or negative version to create the unsharp mask of the original image. It then subtracts 
the blurred version (means combines the unsharp mask) from the original image resulting in an edge enhanced sharpened version of the original version. We have introduced the concept of post-enhancement by unsharp masking in [1] and the results found are quite advanced. In our proposed approach, unsharp masking is employed on the Type-2 fuzzy set enhanced $V$-channel to remove unwanted blurriness that, if still remaining after the initial enhancement, are used to finally produce enhanced and edge sharpened version of the same. The steps and equations involved in our unsharp masking technique [1], Unsharp_Mask() are illustrated below:

Say, $\mathrm{V}(\mathrm{x}, \mathrm{y})$ is the current $\mathrm{V}$-channel and $V^{\prime}(\mathrm{x}, \mathrm{y})$ is its smooth version obtained with anisotropic Gaussian Smoothing [23] with kernel values along with row and column directions respectively $\sigma_{x}=1, \sigma_{y}=8$.

Then, the edge image $L_{e}(\mathrm{x}, \mathrm{y})$ is given by the following equation:

$$
V_{e}(x, y)=V(x, y)-V^{\prime}(x, y)
$$

Now, the final sharpened image $V_{\text {sharp }}(x, y)$ can be obtained by:

$$
V_{\text {sharp }}(x, y)=V(x, y)+c * V_{e}(x, y)
$$

where $c>0.1$ is a scaling constant. We have taken $c=0.5$ through trial and error.

\section{EXPERIMENTS AND RESULTS DISCUSSION}

The supremacy of the proposed approach has been experimentally verified through both subjective and objective evaluations. The approach has been implemented in Matlab in a system with an i-5 processor, 4 GB RAM and Windows 10 operating system. The enhancement technique has been applied to 30 different HE stain images. Originally, these images are of poor contrast and carrying a high level of fuzziness with them, mostly in boundary edges surrounding the different objects, cell nuclei, or region of interests. After enhancement, the results are found to be of improved quality, with sharpness in the edges and hence a better identification of the region of interests. Below are the results for three such images. The results are compared with those obtained by some of the state of the art algorithms and recent techniques: Bora [1], Histogram Equalization, CLAHE and Ensafi et al [7]. 


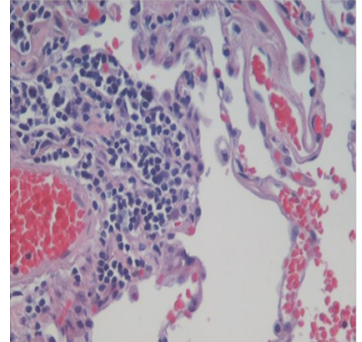

(a)

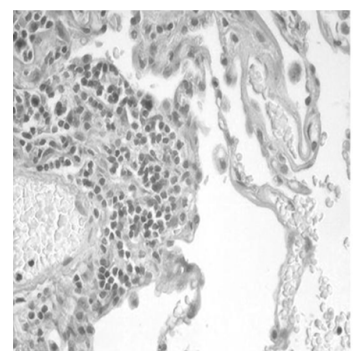

(d)

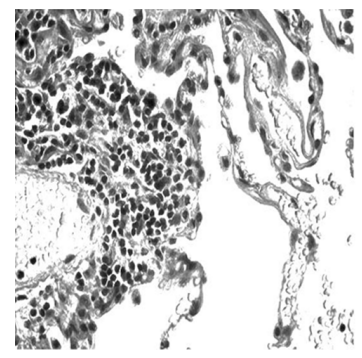

(g)

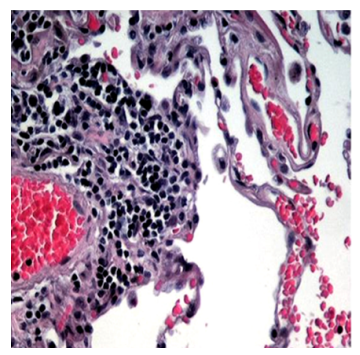

(j)

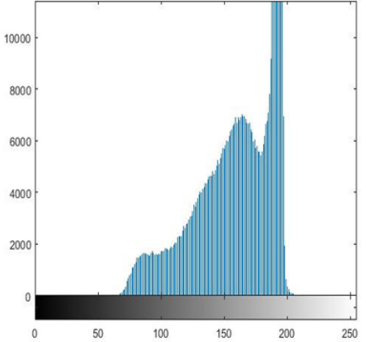

(b)

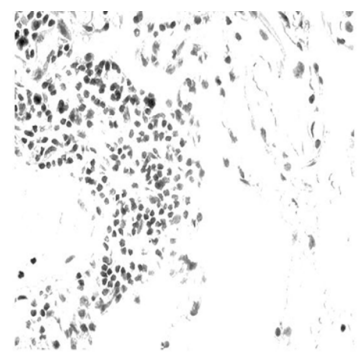

(e)

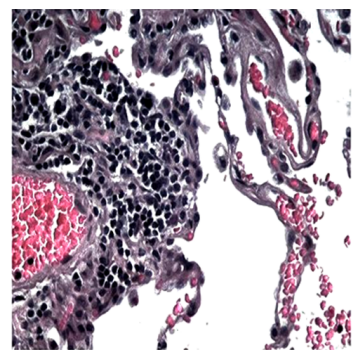

(h)

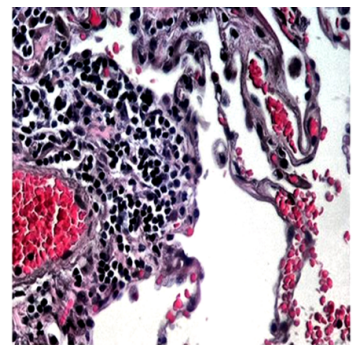

(k)

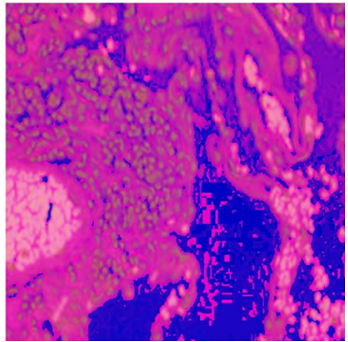

(c)

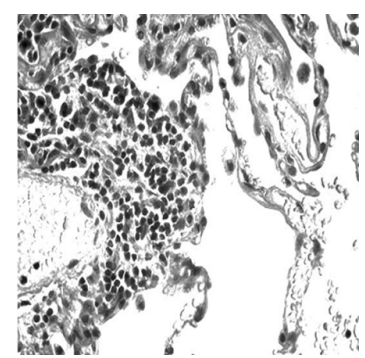

(f)

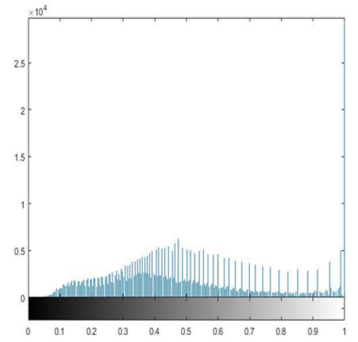

(i)

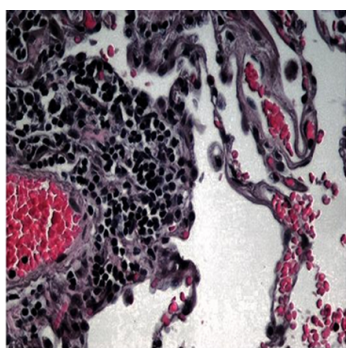

(I)

Figure 8. (a) Original Image; (b) Histogram of the original image; (c) HSV Converted Image; (d) V-channel; (e) Type-2 fuzzy set-based enhancement without contrast enhancement factor; (f) Type-2 fuzzy set enhancement with contrast enhancement factor value 0.5; (g) Post enhancement by Unsharp_Mask();

(i) Final Result of our proposed approach; (j) Enhancement by Bora[1] ;

(k) Enhancement by Ensafi et al. [7]; and (l) Enhancement by CLAHE. 


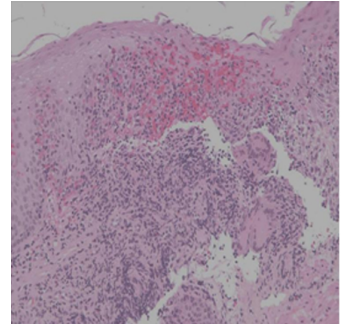

(a)

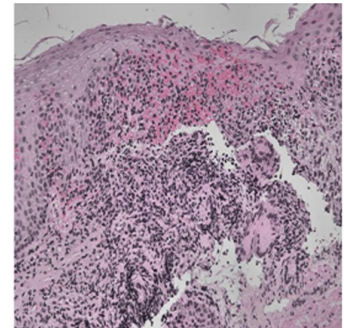

(b)

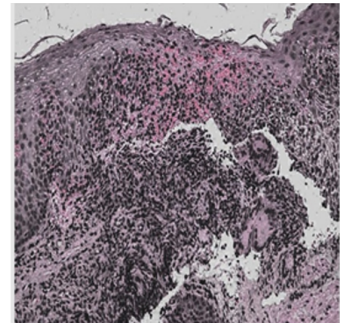

(c)

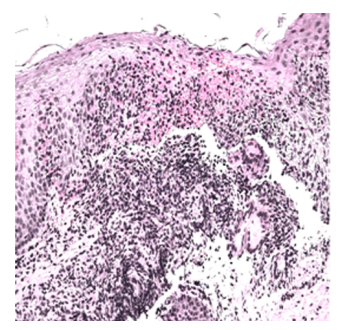

(d)

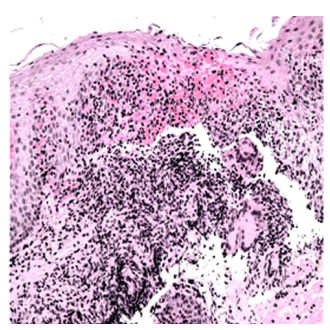

(e)

Figure 9. (a) Original HE Stain Image collected from [24]; (b) Enhancement by CLAHE; (c) Enhancement by Ensafi et al. [7]; (d) Enhancement by Bora [1]; (e) Enhancement by Our proposed approach. Source: own work

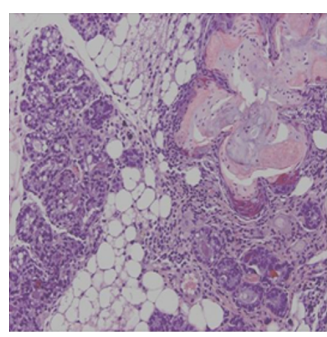

(a)

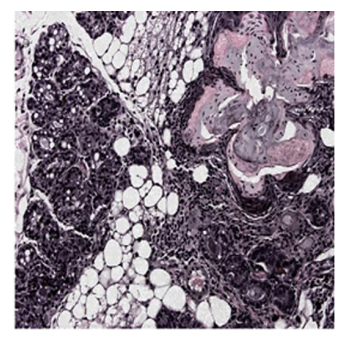

(b)

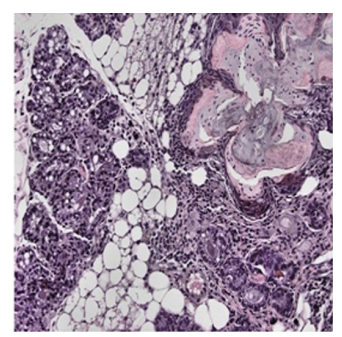

(c)

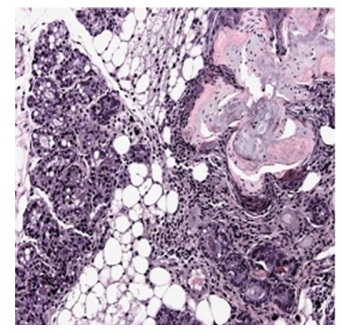

(d)

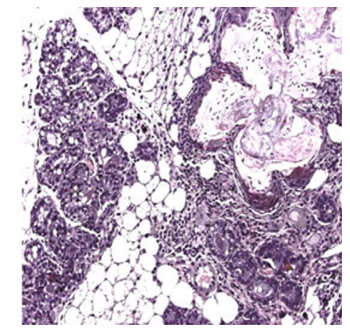

(e)

Figure 10. (a) Original HE Stain Image collected from [25]; (b) Enhancement by CLAHE; (c) Enhancement by Ensafi et al. [7]; (d) Enhancement by Bora [1]; (e) Enhancement by Our proposed approach. 


\subsection{SUBJECTIVE EVALUATION}

From the results, it is clearly visible that cell nuclei and other cell bodies are easily distinguishable from each other in the enhancement result produced by our proposed approach. It implies that vagueness in the edges surrounding the objects in the original image has been removed to an acceptable level. The result obtained through CLAHE is not acceptable in the sense that regions of interest here are not clearly visible. This means this method does not succeed in dealing with the fuzziness involved in the original HE stain color image. The result produced by the method proposed by Ensafi et al. [7] is acceptable in this case. This method is implemented on HSV color space for the color medical image enhancement in this paper. Also, Bora [9] produces a good enhancement result, but not to a level produced by the approach proposed in this paper. The reason is in [1], color space involved is LAB, while in this paper we are employing HSV color space for the color-based computations and HSV has proven itself to be better in this case [17]. Also, the method introduced in [1] is working on a global basis. While, here in this paper, the enhancement is done through local basis. After all, if we focus on the results more closely, then it is obvious that the results produced through our proposed approach are better than those produced with other state of the art techniques.

Subjective evaluations are carried out on the experimental results of our proposed approach by 5 experts from the same research area. They have evaluated the result on the basis of how much fuzziness is removed in the boundary regions of objects present in the image, how much color information is restored with fewer color artifacts, the preservation (or not) of brightness levels, an increase of darkness levels due to over-amplification of noises present in the homogeneous regions which crucially decide the overall visual improvement obtained through a color image enhancement technique for a medical image [9]. Table 1 presents the experts' report: 
Table 1. Subjective evaluation

\begin{tabular}{cccc}
\hline Expert & $\begin{array}{c}\text { Is Visual } \\
\text { Improvement Done } \\
\text { After Enhancement: } \\
\text { Yes/No }\end{array}$ & $\begin{array}{c}\text { Visual Improvement Rating } \\
\text { (Value Ranges from 1 to 10, } \\
\mathbf{1} \text { is the lowest and 10 is the } \\
\text { highest rating) }\end{array}$ & $\begin{array}{c}\text { Viability Rating related } \\
\text { to the application of the } \\
\text { Proposed Approach to } \\
\text { enhance HE Stain image } \\
\text { (Value Ranges From 1 To 10) }\end{array}$ \\
\hline 1 & Yes & 7 & 8 \\
\hline 2 & Yes & 9 & 9 \\
\hline 3 & Yes & 7 & 9 \\
\hline 5 & Yes & 8 & 9 \\
\hline Average & Yes & 8 & $\mathbf{8 . 6}$ \\
\hline
\end{tabular}

Source: own work

So, from the subjective evaluation, it is found that our proposed approach succeeds in producing an efficient enhancement for low contrast HE stain image (with an average rating of $\mathbf{7 . 8}$ ).

\subsection{OBJECTIVE EVALUATION}

To mathematically claim the superiority of our proposed approach, we have to depend on the objective evaluation. For this, we select two metrics: entropy and PSNR.

The entropy of an image can be calculated using the following equation (9):

$$
E=-\operatorname{sum}\left(p \cdot{ }^{*} \log _{2}(p)\right)
$$

where $p$ is the histogram counts obtained from the histogram of the concerned image [26]. A higher value of entropy results in a better enhancement [26].

In the same way, a higher value of PSNR implies less distortion by noise, hence a better enhancement [9]. The PSNR of an image is calculated using the following equation (10):

$$
\operatorname{PSNR}=10 \log _{10}\left(M A X i^{2} / M S E\right)
$$

Where $M A X_{i}$ is the maximum possible pixel value of the image and MSE is the Mean Squared Error which is calculated using the following equation (11): 


$$
\operatorname{MSE}=\sum_{y=1}^{M} \sum_{x=1}^{N}\left[I(x, y)-I^{\prime}(x, y)\right]^{2}
$$

Table 2. Objective Evaluation

\begin{tabular}{|c|c|c|c|c|c|}
\hline \multicolumn{2}{|c|}{ Image No. } & \multirow{2}{*}{$\begin{array}{c}\text { CLAHE } \\
7.8269\end{array}$} & \multirow{2}{*}{$\begin{array}{c}\text { Ensafi et al. [7] } \\
7.8782\end{array}$} & \multirow{2}{*}{$\begin{array}{c}\text { Bora [1] } \\
7.8513\end{array}$} & \multirow{2}{*}{$\begin{array}{c}\text { Our Proposed } \\
\text { Approach }\end{array}$} \\
\hline & Entropy & & & & \\
\hline minge 1 & PSNR & 7.1241 & 7.1284 & 7.1251 & 7.2583 \\
\hline \multirow{2}{*}{ Image 2} & Entropy & 7.3041 & 7.3194 & 7.3103 & 7.3346 \\
\hline & PSNR & 9.3880 & 9.3882 & 9.3934 & 9.4030 \\
\hline \multirow{2}{*}{ Image 3} & Entropy & 7.6971 & 7.6978 & 7.6979 & 7.6988 \\
\hline & PSNR & 9.2988 & 9.3016 & 9.3028 & 9.3246 \\
\hline
\end{tabular}

Source: own work

\section{Entropy Values Comparison}

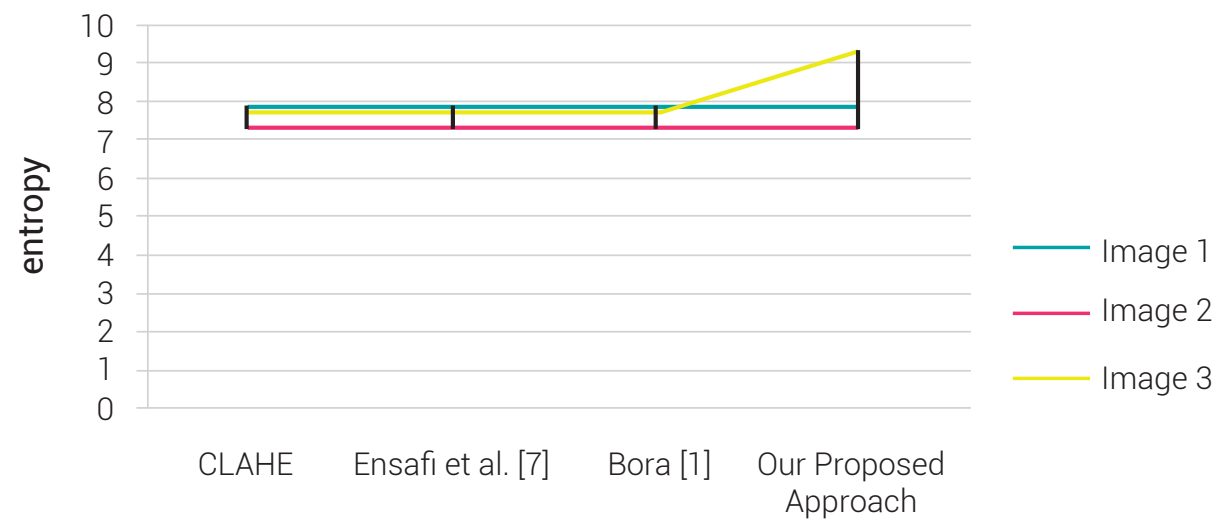

Enhancement Techniques

Figure 11. Entropy Values Comparison

Source: own work 


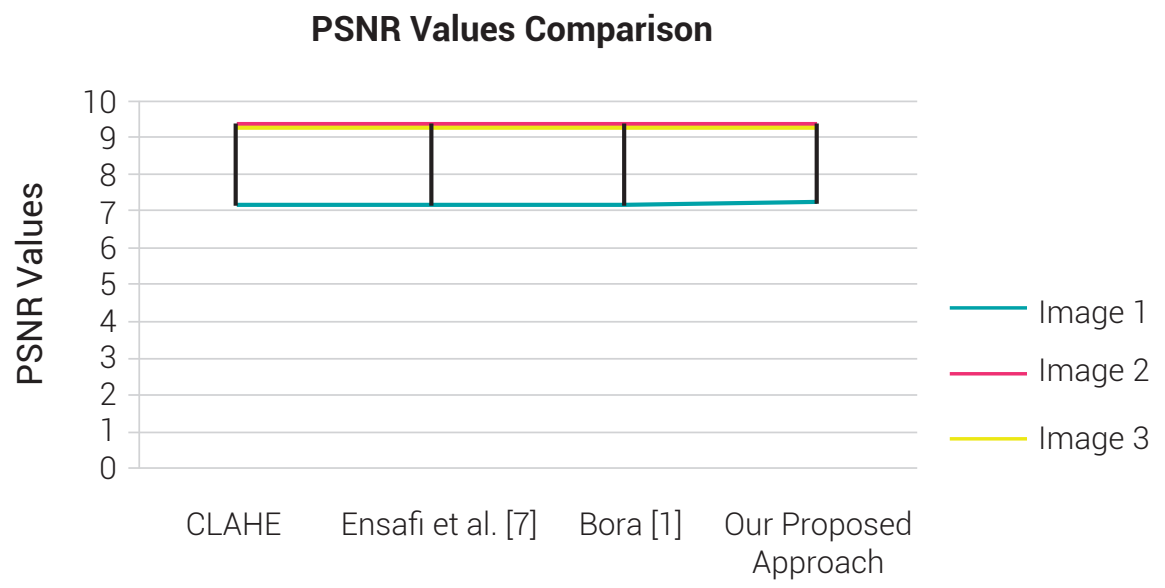

Enhancement Techniques

Figure 12. PSNR Values Comparison Source: own work

So, from the above table (and more clearly from figure 11 and figure 12), the entropy and PSNR values calculated for the proposed approach are higher on average than those calculated from the other state of the art techniques. Hence, the objective evaluation also claims that our proposed approach succeeds in producing a better enhancement of HE stain color images than the other techniques in comparison.

\section{CONCLUSION AND FUTURE RESEARCH}

Only a good quality HE stain image can result in an accurate diagnosis result. These images suffer from the problem of vagueness throughout the boundaries covering important regions of interest. So, to reduce the fuzziness level and to improve the contrast is an important and mandatory part of HE stain image analysis. However, it is observed from previous literature that traditional hard-based techniques, even Type-1 fuzzy set-based techniques are not able to tackle this problem efficiently. Therefore, to deal with this problem, we have to rely on advanced fuzzy logic-based technique. The Type-2 fuzzy set-based technique is one such technique which has the capability to measure and deal with the fuzziness involved in the primary membership function itself. So, an effort has been made to introduce a Type-2 fuzzy set-based local contrast enhancement technique for HE stain image in this paper. This technique involves two-phase enhancement: pre-enhancement using a Type-2 fuzzy set local contrast enhancement technique, local_type2_fuzzy() and 
post-enhancement by an unsharp masking based technique, Unsharp_Mask(). The efficiency of the proposed approach is verified by applying it to several poorly contrasting HE stained color images. The enhancement results are found to be free from vagueness and contrast is improved to a satisfactory level. Also, brightness is preserved and hue values are not altered. Both subjective and objective evaluations prove that the proposed approach succeeds to produce better enhancement of HE stain images than some recent techniques and state of the art techniques. We therefore may conclude that the proposed approach is an efficient preprocessing technique for an improving the analysis of HE stained images.

In our future research, we will focus on analyzing the effectiveness of our proposed approach as a preprocessing technique for segmentation of HE stain images. Segmentation is the most crucial part of the analysis process as it helps to isolate the regions of interest and to focus and investigate only on the segmented area, so, processed HE stain images should be of very good quality and free from vagueness especially on the boundary regions. Our future research will try to inmprove the segmentation outcome through an integrated approach where the preprocessing part will be conducted through the proposed technique. Also, the proposed approach will be extended for edge sharpening for accurate analysis of cell nuclei in HE stain images. Color computation is a very sensitive part of the proposed technique. Although HSV color space was chosen for this particular task, in future we will explore other available color spaces to investigate the possibility of increased efficiency and improvements for the same task.

\section{REFERENCES}

[1] D. J. Bora, "An Ideal Approach for Medical Color Image Enhancement", (n.d.)

[2] G. S. Robinson, "Color edge detection," in Proc. SPIE Symp.Advances Image Transmission Techniques, vol. 87, pp. 126-133, 1976.

[3] M. H. F. Zarandi, and M. Zarinbal, "A new image enhancement method Type-2 Possibilistic C-Mean Approach", IFSA World Congress and NAFIPS Annual Meeting (IFSA/NAFIPS), pp. 11311135, 2013 Joint. [Online]. [Online]. doi: 10.1109/IFSA-NAFIPS.2013.6608559

[4] T. Chaira, "Medical image enhancement using intuitionistic fuzzy set," Ist Inter-national Conference on Recent Advances in Information Technology (RAIT), 2012. [Online]. doi: 10.1109/ rait.2012.6194479. 
[5] T. Chaira, "An improved medical image enhancement scheme using Type II fuzzy set," Applied Soft Computing, 25, pp. 293-308, 2014. [Online]. doi: 10.1016/j.asoc.2014.09.004

[6] J. Gu, L. Hua, X. Wu, H. Yang, and Z. Zhou, "Color medical image enhancement based on adaptive equalization of intensity numbers matrix histogram," International Journal of Automation and Computing, vol. 12, pp. 551-558, 2015. [Online]. doi: 10.1007/s11633-014-0871-9

[7] P. Ensafi, and H. Tizhoosh, "Type-2 Fuzzy Image Enhancement," Lecture Notes in Computer Science, pp.159-166, 2005.

[8] M. Zarinbal, and M. Fazel Zarandi, "Type-2 fuzzy image enhancement: Fuzzy rule based approach”, 2017. [Online]. doi: https://doi.org/10.3233/IFS-130902

[9] D. Bora, "An Efficient Innovative Approach Towards Color Image Enhancement," International Journal of Information Retrieval Research, vol. 8, no. 1, pp.20-37, 2017. [Accessed 1 December 2017]. [Online]. Available: https://www.igi-global.com/article/ an-efficient-innovative-approach-towards-color-image-enhancement/193247

[10] Cytoinformatics.com. (2017). H\&E Stain Hematoxylin and Eosin Staining |Digital Pathology Analysis. [Accessed 1 December 2017]. [Online]. Available: https://cytoinformatics.com/Cyto/ he-stain

[11] Wikipedia.org. (2017). H\u0026E stain. [Accessed 1 December 2017]. [Online]. Available: from: https://en.wikipedia.org/wiki/H\%26E_stain

[12] S. Paxton, M. Adele and Peckham, (2017). The Leeds Histology Guide. Histology.leeds.ac.uk. [Accessed 14 December 2017]. [Online]. Available: http://histology.leeds.ac.uk/what-is-histology/H_and_E.php

[13] M. Gurcan, L. Boucheron, A. Can, A. Madabhushi, N. Rajpoot, and B. Yener, "Histopathological Image Analysis: A Review," IEEE Reviews in Biomedical Engineering, vol. 2, pp.147-171, 2009.

[14] Upload.wikimedia.org. (2017). [Accessed 15 December 2017]. [Online]. Available: https:// upload.wikimedia.org/wikipedia/commons/8/86/Emphysema_H_and_E.jpg

[15] D. Bora, "AERSCIEA: An Efficient and Robust Satellite Color Image Enhancement Approach," Proceedings of the Second International Conference on Research in Intelligent and Computing in Engineering, 2017.

[16] S. Johnson, “Stephen Johnson on Digital Photography," O’Reilly, 2006.

[17] D. Bora, "Importance of Image Enhancement Techniques In Color Image Segmentation: A Comprehensive And Comparative Study," Indian J.Sci.Res, vol. 15, no. 1, pp. 115-131, 2017. 
[18] R. Keys, "Cubic convolution interpolation for digital image processing," IEEE Transactions On Acoustics, Speech, And Signal Processing, vol. 29, no.6, pp. 1153-1160, 1981. [Online]. doi: http://dx.doi.org/10.1109/tassp.1981.1163711

[19] D. Han, "Comparison of Commonly Used Image Interpolation Methods," Proceedings of the 2nd International Conference on Computer Science and Electronics Engineering (ICCSEE 2013), China, pp. 1556-1559, 2013.

[20] V. Patel, and K. Mistree, "A Review on Different Image Interpolation Techniques for Image Enhancement," International Journal of Emerging Technology and Advanced Engineering, vol. 3, no.12, pp. 129-133, 2013.

[21] Z. Zhao, and Y. Zhou, "PLIP based unsharp masking for medical image enhancement" IEEE International Conference on Acoustics, Speech and Signal Processing (ICASSP), 2016. [Online]. doi: 10.1109/icassp.2016.7471874

[22] Unsharp Mask. (2017). Docs.gimp.org. [Accessed 9 May 2017]. [Online]. Available: https:// docs.gimp.org/en/plug-in-unsharp-mask.html.

[23] Spatial Filters - Gaussian Smoothing. Homepages.inf.ed.ac.uk. [Accessed 9 May 2017]. [Online]. Available: http://homepages.inf.ed.ac.uk/rbf/HIPR2/gsmooth.htm.

[24] Medicalxpress.com. (2017). Team finds link between backup immune defense, mutation seen in Crohn's disease. [Accessed 16 December 2017]. [Online]. Available: https://medicalxpress. com/news/2017-07-team-link-backup-immune-defense.html

[25] Pixera.com. (2017). Cite a Website - Cite This For Me. [Accessed 16 December 2017]. [Online]. Available: http://www.pixera.com/sample-images/users/user-0009.jpg

[26] I. Jafar, and H. Ying, "Multilevel component-based histogram equalization for enhancing the quality of grayscale images" IEEE International Conference on Electro/Information Technology, 2007. [Online]. doi:10.1109/eit.2007.4374490. 